\title{
Prevalence, molecular characterization and antibiogram study of Listeria monocytogenes isolated from raw milk and milk products
}

\author{
Nishat Zafar ${ }^{1,2 *}$, Zeeshan Nawaz ${ }^{1}$, Azka Qadeer ${ }^{2}$, Sidra Anam², Rabia \\ Kanwar $^{2}$, Ashiq Ali ${ }^{3}$, Muhammad Mudassar ${ }^{1}$, Muhammad Tariq \\ Javid $^{2}$, Abdullah Zafar ${ }^{2}$ and Asima Tariq ${ }^{2}$ \\ 1. Department of Microbiology, Government College University, Faisalabad (38000)-Pakistan \\ 2. Institute of Microbiology, Faculty of Veterinary Science, University of Agriculture Faisalabad (38000)- \\ Pakistan \\ 3. Department of Pathology, University of Agriculture, Faisalabad (38000)-Pakistan \\ *Corresponding author's email: nishat_zafar@yahoo.com \\ Citation \\ Nishat Zafar, Zeeshan Nawaz, Azka Qadeer, Sidra Anam, Rabia Kanwar, Ashiq Ali, Muhammad Mudassar, \\ Muhammad Tariq Javid, Abdullah Zafar and Asima Tariq. Prevalence, molecular characterization and \\ antibiogram study of Listeria monocytogenes isolated from raw milk and milk products. Pure and Applied \\ Biology. Vol. 9, Issue 3, pp1982-1987. http://dx.doi.org/10.19045/bspab.2020.90211
}

\begin{tabular}{llll}
\hline \hline Received: 01/02/2020 & Revised: 08/05/2020 & Accepted: 04/06/2020 & Online First: 15/06/2020 \\
\hline
\end{tabular}

\section{Abstract}

Foodborne diseases are the primary cause of infections and mortality, especially in developing countries like Pakistan. Listeria monocytogenes is an emerging foodborne infection and a public health threat globally. The present study was designed to detect the prevalence and antimicrobial susceptibility pattern of Listeria monocytogenes in raw milk and milk products. A total of $(n=90)$ samples were collected from different dairy shops of Faisalabad comprising of 40 raw milk, 25 cheese, and 25 yoghurt samples. The samples were collected in sterile plastic bags and shifted to the laboratory in an icebox. The isolation and identification of Listeria monocytogenes was made by standard microbiological and biochemical procedures, while confirmation was done by polymerase chain reaction (PCR) by amplifying the hlyA gene. Antibiotic susceptibility profiling was performed by Kirby Bauer disk diffusion method. The results of the present study showed that among the total 90 samples, 24 (26.66\%) were detected positive for L. monocytogenes with the highest prevalence in raw milk (16) followed by cheese (05) and yoghurt (03). The highest resistance was observed for Penicillin (63.15\%) among the isolates followed by Clindamycin (57.89\%), Ciprofloxacin (26.31\%) and Rifampicin $(26.31 \%)$ while $100 \%$ isolates were found susceptible to Ampicillin, Cephalothin, Chloramphenicol, and Vancomycin. It is concluded that the frequency of Listeria monocytogenes is at an increasing trend in our dairy products, and stringent screening in transportation, processing and storage of dairy products should be needed to reduce the burden of L. monocytogenes infections.

Keywords: Antibiogram; Listeria monocytogenes; Prevalence; Raw milk

Introduction

Listeria monocytogenes (L.

monocytogenes) has been recognized as an emerging foodborne pathogen. The severe life-threatening disease known as listeriosis is caused by the intake of food contaminated with this pathogenic microorganism [1]. Listeriosis is an 
emerging and significant global public health issue. The first reported case of listeriosis was associated with consumption of dairy products, whereas raw cow milk was considered as the carrier of the lethal listeriosis [2]. Pregnant women, children, and old age people are at higher risk of $L$. monocytogenes infection [3]. Prominent clinical outcomes caused by Listeria monocytogenes are sepsis, febrile gastroenteritis, meningoencephalitis, and abortions [4]. Invasive listeriosis could be produced in the babies due to unhygienic conditions in the mother through her placenta. Perinatal listeriosis can cause different defects in neonates like early birth, the conception of a stillborn hatchling and sepsis, or meningitis [5].

Listeria monocytogenes is usually found in compost and silage (2-8\%) within the dairy farm. Some other prominent areas for Listeria presence are steady water in channels, surfaces, and washing areas [6]. Mostly the milk becomes contaminated with Listeria species from the unhygienic environment of farm [7].

Antimicrobial resistance has been increasing day by day due to the emergence of resistant bacteria [8]. Numerous outbreaks of listeriosis were confirmed to be related to the intake of raw milk and initiating immense attention in the milk product manufacturing [9]. Keeping in view the facts mentioned above and the increasing trend of antibiotic resistance, the present study was designed to determine the prevalence and antibiotic susceptibility testing of L. monocytogenes in raw milk and milk products.

\section{Materials and methods}

\section{Sample collection and transportation}

A total of 90 samples (40 raw milk, 25 cheese, and 25 yoghurt) were collected from different milk shops of Faisalabad. These samples were collected in sterile plastic bags and immediately transported to the laboratory under the aseptic condition in ice boxes. Each sample was mixed in peptone water and incubated at $30^{\circ} \mathrm{C}$ overnight followed by inoculation of $(5 \mathrm{ml})$ suspension in Fraser Broth $(95 \mathrm{ml})$ and incubation at $30^{\circ} \mathrm{C}$ for $48 \mathrm{hrs}$ for enrichment [10].

\section{Isolation and identification of Listeria monocytogenes}

A loopful of each enriched sample was then streaked on Polymyxin Acriflavin Lithiumchloride Ceftazidime Esculin Mannitol (PALCAM) agar medium plates and incubated overnight at $37^{\circ} \mathrm{C}$ aerobically. The identification was made based on colony characters, Gram's staining, and biochemical characters. The pattern of hemolysis was detected by streaking the isolated colonies on blood agar [11, 12].

\section{Confirmation of $L$. monocytogenes}

The isolated Listeria colonies were subjected to DNA extraction with the help of a commercially available kit (Thermo Scientific, USA). Amplification of hemolysin (hly A) gene was done by PCR with the help of specific primers (F: 5'CGGAGGTTCCGCAAAAGATG-3') and (R: 5'-CCTCCAGAGTGATCGATGTT3 ). The PCR products were analyzed by electrophoresis [13].

\section{Antibiotic susceptibility profiling}

Kirby Bauer disk diffusion technique was used for the detection of antibiotic susceptibility of isolates. Antibiotic disks used were; Penicillin, Ampicillin, Trimethoprim-sulfamethoxazole,

Vancomycin, Clindamycin, Rifampicin chloramphenicol, tetracycline and ciprofloxacin, cephalothin and gentamicin. The resistance and susceptibility pattern was determined and compared through clinical laboratory standard institute (CLSI) standard guidelines [14].

\section{Results}

\section{Frequency of Listeria monocytogenes}

The results of the present study showed that out of a total 90 samples collected, 24 (26.66\%) were found positive for $L$. monocytogenes based on standard microbiological. The highest percentage $L$. monocytogenes was found in raw milk samples $40 \%$ (16/40), while cheese and yogurt showed 20\% (5/25) and 12\% (3/25), respectively, as shown in (Table 1$)$. 


\section{Molecular detection of Listeria monocytogenes}

All the isolates were subjected to molecular detection of an L. monocytogenes virulence factor Listeriolysin $\mathrm{O}$, which is encoded by the $h l y$ A gene. It was recorded that all the $(n=24)$ isolates showed positive amplification of the $h l y A$ gene with a $234 \mathrm{bp}$ band, as shown in (Fig. 1).

Table 1. Occurrence of Listeria monocytogenes in raw milk and milk products

\begin{tabular}{|c|c|c|c|}
\hline Type of Sample & No. of Samples & Positive Samples & Positive Percentage \\
\hline Raw Milk & 40 & 16 & $40 \%$ \\
\hline Cheese & 25 & 05 & $20 \%$ \\
\hline Yogurt & 25 & 03 & $12 \%$ \\
\hline Total & 90 & 24 & $26.66 \%$ \\
\hline
\end{tabular}

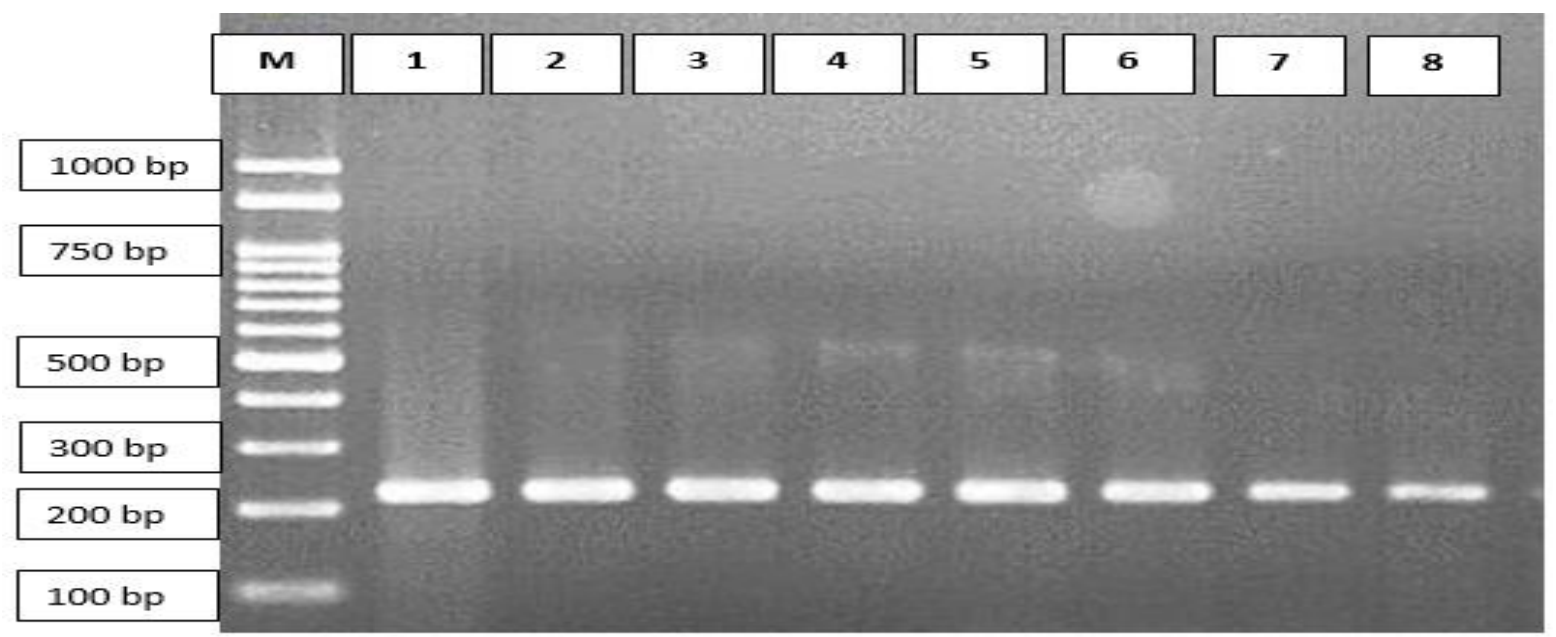

Figure 1. DNA marker in lane $M$ and amplified product of the $h l y A$ gene of $234 \mathrm{bp}$ from lane 1-8

Antibiotic susceptibility test

The antibiotic susceptibility profiling of $L$. monocytogenes was performed by Kirby Bauer disk diffusion method, and it was observed that the highest resistance was found for Penicillin (63.15\%) among the isolates followed by Clindamycin

Table 2. Percentage resistance pattern of $L$. monocytogenes against different antibiotics

\begin{tabular}{|c|c|c|c|}
\hline Antibiotics & Susceptible & Intermediate & Resistant \\
\hline Ampicillin & $19(100 \%)$ & $00(0 \%)$ & $00(0 \%)$ \\
\hline Ciprofloxacin & $12(63.15 \%)$ & $02(10.52 \%)$ & $05(26.31 \%)$ \\
\hline Cephalothin & $19(100 \%)$ & $00(0 \%)$ & $00(0 \%)$ \\
\hline Clindamycin & $07(36.84 \%)$ & $01(5.26 \%)$ & $11(57.89 \%)$ \\
\hline Chloramphenicol & $19(100 \%)$ & $00(0 \%)$ & $00(0 \%)$ \\
\hline Gentamycin & $15(78.94 \%)$ & $02(10.52 \%)$ & $02(10.52 \%)$ \\
\hline Penicillin & $06(31.57 \%)$ & $01(5.26 \%)$ & $12(63.15 \%)$ \\
\hline Rifampicin & $14(73.68 \%)$ & $00(0 \%)$ & $05(26.31 \%)$ \\
\hline Trimethoprimsulfamethoxazol & $16(84.21 \%)$ & $01(5.26 \%)$ & $02(10.52 \%)$ \\
\hline Tetracycline & $13(68.42 \%)$ & $04(21.05 \%)$ & $02(10.52 \%)$ \\
\hline Vancomycin & $19(100 \%)$ & $00(0 \%)$ & $00(0 \%)$ \\
\hline
\end{tabular}

(57.89\%), Ciprofloxacin (26.31\%) and Rifampicin $(26.31 \%)$. All the isolates were found sensitive to Ampicillin (100\%), chloramphenicol (100\%), vancomycin $(100 \%)$, and cephalothin (100\%), as shown in (Table 2). 


\section{Discussion}

Today, food safety is everybody's concern, and it is tough to find someone who has not encountered an unpleasant moment of foodborne illness at least once in a year. The majority of the foodborne diseases are self-limiting and mild, but severe cases can occur in high-risk groups, including infants, young children, the elderly, and the immunocompromised persons [15]. Listeriosis is caused by Listeria monocytogenes, a highly fatal opportunistic pathogen resulting in abortions, sepsis, and meningoencephalitis [16]. Listeriosis is a zoonotic problem generally caused by the utilization of milk and milk products [8]. The results of the present study showed that out of a total of 90 samples collected, 24 (26.66\%) were found positive for $L$. monocytogenes. The findings of Gohar et al. [17] showed a $13.6 \%$ prevalence from Pakistan, Hosseini et al. [18] showed 19.04\% from Iran, and Yakubu et al. [19] showed $22.4 \%$ from Nigeria. This increased prevalence of Listeria monocytogenes in the present study is due to improper milking, unhygienic handling, poor transportation, and storage facilities.

It was recorded that raw milk had the highest percentage of contamination $40 \%$, while yoghurt had at least $12 \%$. A similar trend in the results was achieved by Gohar et al. [17] in Pakistan, Sheela, and Shrinithivihahshini, [20] in India and Hosseini et al. [18] in Iran. This low prevalence of Listeria monocytogenes in yoghurt is due to the production of lactic acid during yoghurt manufacturing by Lactobacillus species, which suppresses the growth of harmful bacteria. This fact is also supported previously by scientists that lactic acid bacteria produce some compounds which reduce the levels of $L$. monocytogenes in yoghurt $[21,22]$.

The results of the present study also showed that Penicillin $(63.15 \%)$ and clindamycin $(57.89 \%)$ were found resistant to isolates of L. monocytogenes, which is also under the findings of (Akrami-Mohajeri et al. [23] and Harakeh et al. [24]. The resistance of $L$. monocytogenes isolates from different dairy products to common antibiotics. Penicillin, tetracycline, and gentamicin is evident [19, 25]. In contrast, the current study revealed a $100 \%$ resistance to Ampicillin, chloramphenicol, and Vancomycin. A similar type of result was previously mentioned in Nigeria [19] and Ethiopia [26]. The emergence of multidrugresistant (MDR) Listeria monocytogenes is also reported in humans and animals, which is due to the irrational use of antibiotics among the food animals $[27,28]$.

\section{Conclusion}

The results of this study conclude that increasing the trend of Listeria monocytogenes in milk and dairy products is an alarming situation and a public health threat that can cause morbidity and mortality outbreaks. The milk for human consumption and production of milk products must be pasteurized or at least boiled to protect young, pregnant women and immune-compromised individuals from this infection.

\section{Authors' contributions}

Conceived and designed the experiments: MZ Nawaz, Performed the experiments: $\mathrm{N}$ Zafar, Analyzed the data: S Anam, R Kanwar, MT Javid \& A Tariq, Contributed materials/ analysis/ tools: MZ Nawaz, Wrote the paper: A, Ali, A Qadeer, N Zafar, A Zafar \& M Mudassar.

\section{Acknowledgement}

The author would like to thanks all the coauthors and laboratory staff during the research.

\section{References}

1. Liu D (2006). Identification, subtyping, and virulence determination of Listeria monocytogenes, an outstanding foodborne pathogen. $J$ Medical Microbio 55: 645-659.

2. Pintado C, Oliveira A, Pampulha M \& Ferreira M (2005) Prevalence and characterization of L. monocytogenes isolated from soft cheese. London $J$ Food Microbio 22: 79-85. 
3. Scallan E, Hoekstra RM \& Angulo FJ (2011). Foodborne illness acquired in the United States major pathogens. Emerg Infect Dis 17: 7-15.

4. Schlech WF \& Acheson D (2000). Foodborne listeriosis. Clin Infect Dis 31: 770-775.

5. Swaminathan $B$ \& Gerner-Smidt $P$ (2007). The epidemiology of human listeriosis. Microbes infect 9: 12361243.

6. Sarfaz M, Ashraf Y \& Ashraf S (2017). A Review: Prevalence and antimicrobial susceptibility profile of Listeria species in milk. Matrix Sci Med 1: 03-09.

7. Savadogo A, Ouattara CAT, Savadogo PW, Ouattara AS, Barro N $\&$ Traore AS (2004). Microorganisms involved in Fulani traditional fermented milk in Burkina Faso. Pak J Nutr 3: 134-139.

8. Morobe I, Obi C, Nyila M, Gashe B \& Matsheka M (2009). Prevalence, antimicrobial resistance profiles of Listeria monocytogenes from various foods in Gaborone, Botswana. Afr $J$ Biotechnol 8: 6383-6387.

9. Silk BJ, Date KA, Jackson KA, Pouillot R, Kristin GH \& Lewis MG (2012). Invasive listeriosis in foodborne diseases active surveillance network (Food Net), 2004-2009: Further targeted prevention needed for higher-risk groups. Clin Infect Dis 54: 396-404.

10. Al-Mariri A, Younes AA \& Ramadan L (2013). Prevalence of Listeria spp. in raw milk in Syria. Bulg $\mathrm{J}$ Vet Medicin 16: 112-122.

11. Aygun O \& Pehlivanlar S (2006). Listeria spp. in the raw milk and dairy products in Antakya, Turkey. Food Control 17: 676-679.

12. Maijala R, Lyytikäinen $\mathrm{O}$, Johansson T, Autio T, Aalto T, Haavisto L \& Honkanen-Buzalski T (2001). Exposure of Listeria monocytogenes within an epidemic caused by butter in
Finland. Int J Food Microbiol 70: 97109.

13. Cooray KJ, Nishibori $\mathrm{T}$, Xiong $\mathrm{H}$, Matsuyama T, Fujita M \& Mitsuyama M (1994). Detection of multiple virulence-associated genes of Listeria monocytogenes by PCR in artificially contaminated milk samples. Appl Environ Microbiol 60: 3023-3026.

14. Ilyas S, Qamar MU, Rasool MH, Abdulhaq N \& Nawaz Z (2016). Multidrug-resistant pathogens isolated from ready-to-eat salads available at a local market in Pakistan. Brit Food J 118: 2068-2075.

15. Fleury MD, Stratton J, Tinga C, Charron DF \& Aramini J (2008). A descriptive analysis of hospitalization due to acute gastrointestinal illness in Canada, 1995-2004. Can J Public Health 99: 489-493.

16. Boland JAV, Kuhn M, Berche P, Chakraborty T, Bernal GD, Goebel W, Zorn BG, Wehland J \& Kreft J (2001). Listeria pathogenesis and molecular virulence determinants. Clin Microbiol Rev 14: 584-640.

17. Gohar S, Abbas G, Sajid S, Sarfraz M, Ali S, Ashraf M, Aslam R \& Yaseen K (2017). Prevalence and antimicrobial resistance of Listeria monocytogenes isolated from raw milk and dairy products. Matrix Sci Med 1: 10-14.

18. Hosseini AH, Sharifan A \& Tabatabaee A (2014). Isolation of Listeria monocytogenes from meat and dairy products. $J$ Med Microbiol Infec Dis 2: 159-162.

19. Yakubu Y, Salihu M, Faleke O, Abubakar M \& Junaidu A (2012) Prevalence and antibiotic susceptibility of Listeria monocytogenes in raw milk from cattle herds within Sokoto Metropolis, Nigeria. Sokoto J Veterinary Sci 10: 13-17.

20. Sheela MM \& Shrinithivihahshini ND (2017). Pervasiveness of Listeria monocytogenes in milk and dairy 
products. J Food Microbiol Saf Hyg 2:125-129.

21. Arques JL, Rodriguez E, Gaya P, Medina M \& Nunez M (2005). Effect of combinations of high pressure treatment and bacteriocin producing Lactic acid bacteria on the survival of Listeria monocytogenes in raw milk cheese. Int Dairy J 15: 893-900.

22. Vermeulen A, Gysemans KPM, Bernaerts K, Geeraerd AH \& Van Impe JF (2007). Influence of $\mathrm{pH}$, water activity and acetic acid concentration on Listeria monocytogenes at $7^{\circ} \mathrm{C}$ : data collection for the development of a growth/no growth model. Int $J$ Food microbial 114: 332-341.

23. Akrami-Mohajeri F, Derakhshan Z, Ferrante M, Hamidiyan N, Soleymani M, Conti GO \& Tafti R D (2018). The prevalence and antimicrobial resistance of Listeria spp in raw milk and traditional dairy products delivered in Yazd, central Iran (2016). Food Chem Toxicol 114: 141-144.

24. Harakeh S, Saleh I, Zouhairi O, Baydoun E, Barbour E \& Alwan N. (2009). Antimicrobial resistance of Listeria monocytogenes isolated from dairy-based food products. Sci Total Environ 407: 4022-4027.

25. Olaimat AN, Al-Holy MA, Shahbaz HM, Al-Nabulsi AA, Abu-Ghoush MH, Osaili TM \& Holley RA (2018). Emergence of antibiotic resistance in Listeria monocytogenes isolated from food products: a comprehensive review. Compr Rev Food Sci F 17: 1277-1292.

26. Girma Y \& Abebe B (2018). Isolation, identification and antimicrobial susceptibility of Listeria species from raw bovine milk in Debre-Birhan Town, Ethiopia. J Zoonotic Dis Public Health 2: 4-7.

27. Marian M, Sharifah A, Zuraini M, Son R, Maimunah M \& Lee H (2012). MPN-PCR detection and antimicrobial resistance of $L$. monocytogenes isolated from raw and ready to eat food in Malaysia. Food Control 28: 309-314.

28. Maha A, AL-Ashmawy M, Mayada M \& Khaled H (2014). Prevalence, detection methods and antimicrobial susceptibility of Listeria monocytogens isolated from milk and soft cheeses and its zoonotic importance. W Appl Sci J 29: 869-878. 